\title{
Multi-Item Production Lot Sizing with Postponement, External Source for Common Parts, and Adjustable Rate for End Products
}

\author{
Singa Wang Chiu \\ Department of Business Administration, \\ Chaoyang University of Technology, Taichung, Taiwan. \\ E-mail: swang@cyut.edu.tw \\ Hua Yao Wu \\ Physics Department College of Liberal Arts and Sciences, \\ State University of New York, Oswego, NY, USA. \\ E-mail: huayao.wu@oswego.edu \\ Tiffany Chiu \\ Anisfield School of Business, \\ Ramapo College of New Jersey, Mahwah, NJ, USA. \\ E-mail: tchiu@ramapo.edu \\ Yuan-Shyi Peter Chiu \\ Department of Industrial Engineering \& Management, \\ Chaoyang University of Technology, Taichung, Taiwan. \\ Corresponding author: ypchiu@cyut.edu.tw
}

(Received on December 17, 2020; Accepted on February 11, 2021)

\begin{abstract}
This study considers a multi-item production lot-size problem incorporating postponement, an external source for common parts, and an adjustable-rate for end products. Dealing with product variety, timely requirements, and limited in-house capacity has led production managers to seek manufacturing schemes and utilization-reduction strategies that can help them meet customer needs, smoothen fabrication schedules, and lower overall manufacturing expenses. We propose a two-stage manufacturing scheme. The first stage produces common parts for multiproduct incorporating a partial supply from an outside contractor to reduce utilization/uptime. Stage two fabricates all end products using an adjustable-rate to reduce the uptime further. We build a model to characterize the problem's features and use optimization methods to derive the optimal rotation cycle time in order to help managers make cost-effective lot-size decisions and allow manufacturers to gain competitive advantages. A numerical illustration validates the model's capability and applicability. This study makes two important contributions: (1) It offers a decision-support model for studying such a particular batch-size problem and deciding the optimal rotation cycle time, and (2) it identifies the individual/collective influence of dual uptime-reduction strategies on the operating policy and various performance indexes to help facilitate managerial decision-making.
\end{abstract}

Keywords- Multi-item lot sizing, Two-stage fabrication scheme, Common parts, Postponement, External source, Adjustable rate.

\section{Introduction}

This study examines a multi-item production lot-size problem incorporating postponement, the external source for common parts, and adjustable-rate for end products. Timely requirements, product variety, and limited in-house capacity have urged production managers to continually seek different manufacturing schemes and utilization-reduced strategies to meet customers' needs, 
International Journal of Mathematical, Engineering and Management Sciences

Vol. 6, No. 3, 787-804, 2021

https://doi.org/10.33889/IJMEMS.2021.6.3.047

smoothen fabrication schedules, and lower the total manufacturing expenses. During the multiproduct fabrication planning stage, managers consider a postponement strategy to delay product differentiation and reduce the orders' response time for end products. Gerchak and Henig (1986) examined the implication and impact of component commonality on the "assemble-to-order" fabrication processes. They explored dynamic and static situations for product-specific parts and other combined parts to disclose the characteristics and managerial implications in these different situations. van Mieghem and Dada (1999) examined the price versus fabrication postponement issues by focusing on completion and capacity. Through building a two-stage decisional model to enable comparing/analyzing the potential benefits of postponement strategy from three different decisions: investing capacity, fabrication quantity, price. As a result, they revealed the collective effect of competition, the operational decision's timing, and uncertainty on a firm's strategic investment decision and value. Schulze and Li (2009) considered a multiproduct logistic network featuring commonality and postponement with the aim to analyze the influence of product commonality and the postponement strategy on planning/allocating the locations. İnkaya et al. (2018) examined a two-stage supply chain focusing on the collective impact of competition, coordination, and cost structure on vertically differentiated products' pricing and variety decisions. Through numerical experiments, they compared different scenarios of product differentiation/ coordination between manufacturers and assembly firms. The performance evaluation measures were the partial differentiation option, product competition strength, cost of bill-of-materials, and products' quality levels. Recent studies (Chiu et al., 2019, 2020a; Jabbarzadeh et al., 2019; Le Pape and Wang, 2020; Wu et al., 2021) also examined the impact of different postponement schemes on manufacturing systems, supply chains, and corporation management.

The commonly used uptime-reduction strategies to meet timely customer's orders and smoothen machine utilization fabrication include outsourcing and expedited rate. This study considers outsourcing a portion of a batch's common components to shorten the needed uptime in stage one. Daugherty and Dröge (1997) examined the impact of differences in external logistical services usage levels on corporations of various organizational structures. Lee-Mortimer (2006) examined the correlations between improved product design studied and outsourcing assembly and manufacturing tasks. Through surveyed/studied numerous outsourcing cases/firms, the author obtained the overseas manufactures' cost-benefit analytical details and researched their current product design to seek correlations that can facilitate managerial operating decision-making. Elahi (2013) built a make-to-stock, multiple-vendors single-buyer queueing model to investigate the best outsourcing competition parameters. The model considered each vendor a queueing system, used a proportional allocating function, and inventory and service levels as competition parameters to study the correlations between the parameters to maximize the buyer's service level. Chiu et al. (2020b) derived the optimal rotation cycle decision for a multi-item finite production rate-based system with a delayed differentiation strategy and a partial common-component outsourcing option. Recent studies (Akkermans et al., 2019; Chiu et al., 2020c, d; Iqbal et al., 2020) also examined the impact of various outsourcing policies on supply chains, production systems, and corporation management.

Further, we consider an expedited rate for manufacturing multiple end items to further cut short stage two's production uptime. Boucher (1987) investigated the maximization of robot fabrication rates in the operations of simple component insertions. The author formulated and analyzed the problem to decide the robot's stopping rules to focus on the consistency of the robot's dimensional tolerances and variability. Al-Fawzan and Al-Sultan (1997) extended the economic production quantity model (EPQ model) by incorporating a controllable fabrication rate. The authors built 
mathematical models with a specific search algorithm to examine the EPQ problems with and without permitted shortages. Their objectives were to simultaneously derive the optimal fabrication lot-size and rate from minimizing the problems' total expenses. Gharbi et al. (2006) explored a multi-item multi-machine manufacturing system with different setups, unreliable equipment, and controllable rates. The authors applied several methods (e.g., the response surface, stochastic optimal control, discrete-event simulation, and experimental design) to resolve the complex problem. Their objectives were to determine the optimal setup order and manufacturing rates to minimize the system's operating expenses. The authors examined cases of different numbers of machines with dissimilar failure and repair-time distribution to validate their model's applicability. Sajadieh and Larsen (2015) examined a producer-retailer coordinated two-stage supply chain considering random yield, fixed setup cost, backlogs, and stochastic demand. The authors proposed the Markovian chain to analyze and explore the optimal supply-chain decision. Their study used several cases to validate their study's applicability. Recent works (Fathallah et al., 2019; Lin et al., 2019; Demić et al., 2020; Lesmono et al., 2020; Moin et al., 2020; Yadavalli et al., 2020; Glock and Grosse, 2021;) investigated the effect of variable manufacturing rates on various aspects of fabrication systems and supply chain systems. Since few past works emphasized multi-item production lot-sizing problems with postponement and dual uptime-reduction strategies, we intend to fill the gap.

\section{Material and Methods}

\subsection{Problem Description and Notation}

This study explores a multi-item production lot sizing with postponement, external source for common parts, and adjustable-rate for end products. The following Nomenclature helps describe the studied two-stage delayed differentiation production model:

$\lambda_{i} \quad=$ end product $i$ 's annual demand (where $i=1,2, \ldots, L$ ),

$t_{1, i} \quad=$ end product $i$ 's uptime in stage two,

$t_{2, i} \quad=$ depleting time of end product $i$,

$Q_{i} \quad=$ end product $i$ 's lot size,

$P_{\mathrm{T} 1, i} \quad=$ adjustable manufacturing rate of end product $i$ per year,

$P_{1, i} \quad=$ ordinary production rate of end product $i$ per year,

$\alpha_{1, i} \quad=$ the connecting parameter between $P_{1, i}$ and $P_{\mathrm{T} 1, i}$,

$K_{\mathrm{T}, i}=$ end product $i$ 's setup cost when adjustable-rate is used,

$K_{i} \quad=$ ordinary setup cost of end product $i$,

$\alpha_{2, i} \quad=$ the connecting parameter between and $K_{i}$ and $K_{\mathrm{T}, i}$,

$C_{\mathrm{T}, i}=$ end product $i$ 's unit cost when using adjustable-rate,

$C_{i} \quad=$ end product $i$ 's ordinary unit cost,

$\alpha_{3, i}=$ the connecting parameter between $C_{i}$ and $C_{\mathrm{T}, i}$,

$H_{1, i}=$ end product $i$ 's inventory status when its uptime finishes,

$h_{1, i} \quad=$ end product $i$ 's unit holding cost,

$S_{i} \quad=$ end product $i$ 's setup time,

$t_{i}^{*} \quad=$ the optimal total uptimes of end products,

$T_{\mathrm{Z}} \quad=$ rotation cycle time - the decision variable,

$t_{1,0}=$ the uptime of common parts in stage one,

$t_{2,0}=$ the depletion time of common parts,

$\lambda_{0}=$ common part's annual demand,

$Q_{0} \quad=$ common part's in-house lot-size,

$\pi_{0} \quad=$ outsourcing proportion of common parts per batch,

$\gamma=$ common part's completion rate, 
International Journal of Mathematical, Engineering and Management Sciences

Vol. 6, No. 3, 787-804, 2021

https://doi.org/10.33889/IJMEMS.2021.6.3.047

$P_{1,0}=$ common part's in-house annual manufacturing rate,

$K_{\pi 0} \quad=$ outsourcing's setup expense,

$C_{\pi 0} \quad=$ unit cost per outsourced part,

$H_{2,0} \quad=$ common part's stock level when outsourced items are received,

$H_{1,0}=$ common part's level when uptime ends,

$H_{i} \quad=$ common part's level when end product $i$ 's uptime completes,

$K_{0} \quad=$ common part's production setup expense,

$\beta_{1,0} \quad=$ the relating parameter between $K_{0}$ and $K_{\pi 0}$,

$C_{0} \quad=$ unit manufacturing cost per common part,

$\beta_{2,0}=$ the relating parameter between $C_{0}$ and $C_{\pi 0}$,

$h_{1,0}=$ common part's unit holding cost,

$i_{0}=$ the relating parameter between holding and unit costs (i.e., $h_{1,0}=i_{0} C_{0}$ ),

$t_{0}{ }^{*} \quad=$ the optimal uptime for production of common parts,

$S_{0} \quad=$ setup time for common part,

$I(t)_{I} \quad=$ inventory level at time $t$,

$T C\left(T_{\mathrm{Z}}\right)=$ total production-inventory expense per cycle,

$\operatorname{TCU}\left(T_{\mathrm{Z}}\right)=$ total production-inventory expense per unit time.

The studied multi-item lot-size problem has the following characteristics/assumptions: (1) This study uses a single-machine delayed differentiation two-stage production scheme. Stage one makes all required common parts, and stage two fabricates multiple finished products under a rotation cycle discipline. (2) Both the annual demand rates of multi-item and the completion rate of the common part are assumed constant, e.g., if $\gamma=0.5$, then the end product's fabrication rate two times as much as the ordinary rate of a single-stage system. (3) To shorten the uptime in stage one, an external source is used to supply a $\pi_{0}$ portion of common parts. (4) To further reduce the total uptimes in stage two, an expediting rate with factor $\alpha_{1, i}$ is used to fabricate multiple end products. The influence of $\pi_{0}$ and $\alpha_{1, i}$ on relevant fabrication-rate and cost parameters, as shown below:

$$
\begin{aligned}
& P_{T 1, i}=P_{1, i}\left(1+\alpha_{1, i}\right) \\
& K_{T, i}=K_{i}\left(1+\alpha_{2, i}\right) \\
& C_{T, i}=C_{i}\left(1+\alpha_{3, i}\right) \\
& K_{\pi 0}=K_{0}\left(1+\beta_{1,0}\right) \\
& C_{\pi 0}=C_{0}\left(1+\beta_{2,0}\right)
\end{aligned}
$$

Figure 1 exhibits the level of stocks in our proposed problem featuring postponement, an external source for common parts, and an adjustable-rate for finished products. It shows the common parts' level stacks to $H_{1,0}$ when in-house uptime $t_{1,0}$ completes; meantime, the external source supplies the outsourced items to bring common parts' level to $H_{2,0}$ before stage two begins. Then, finished product $i$ 's level accumulates to $H_{1, i}$, when $t_{1, i}$ ends. Finally, the stocks of product $i$ diminish under a continuous transporting police.

\subsection{Formulations and Solution Process}

In stage two, the annual demand $\lambda_{i}$ of multiple finished products must be satisfied $(i=1,2, \ldots, L)$ by a batch production plan with an adjustable-rate $P_{\mathrm{T} 1, i}$. Observing Figure 1, the relevant formulas 
International Journal of Mathematical, Engineering and Management Sciences

Vol. 6, No. 3, 787-804, 2021

https://doi.org/10.33889/IJMEMS.2021.6.3.047

in stage two include lot size $Q_{i}$, uptime, stock level, depletion time, and cycle length can be straightforwardly gained as follows:

$$
\begin{aligned}
Q_{i} & =\lambda_{i} T_{Z} \\
t_{1, i} & =\frac{Q_{i}}{P_{T 1, i}} \\
H_{1, i} & =\left(P_{T 1, i}-\lambda_{i}\right) t_{1, i} \\
t_{2, i} & =\frac{H_{1, i}}{\lambda_{i}} \\
T_{Z} & =t_{1, i}+t_{2, i}, \text { where } i=0,1,2, \ldots, L
\end{aligned}
$$

All required common parts for making end product $i$ begin to deplete a $Q_{i}$ quantity from $H_{2,0}$ to $H_{i}$. Figure 2 shows a clear view of the common parts' level in stage two, and equations (11) to (14) exhibit the details.

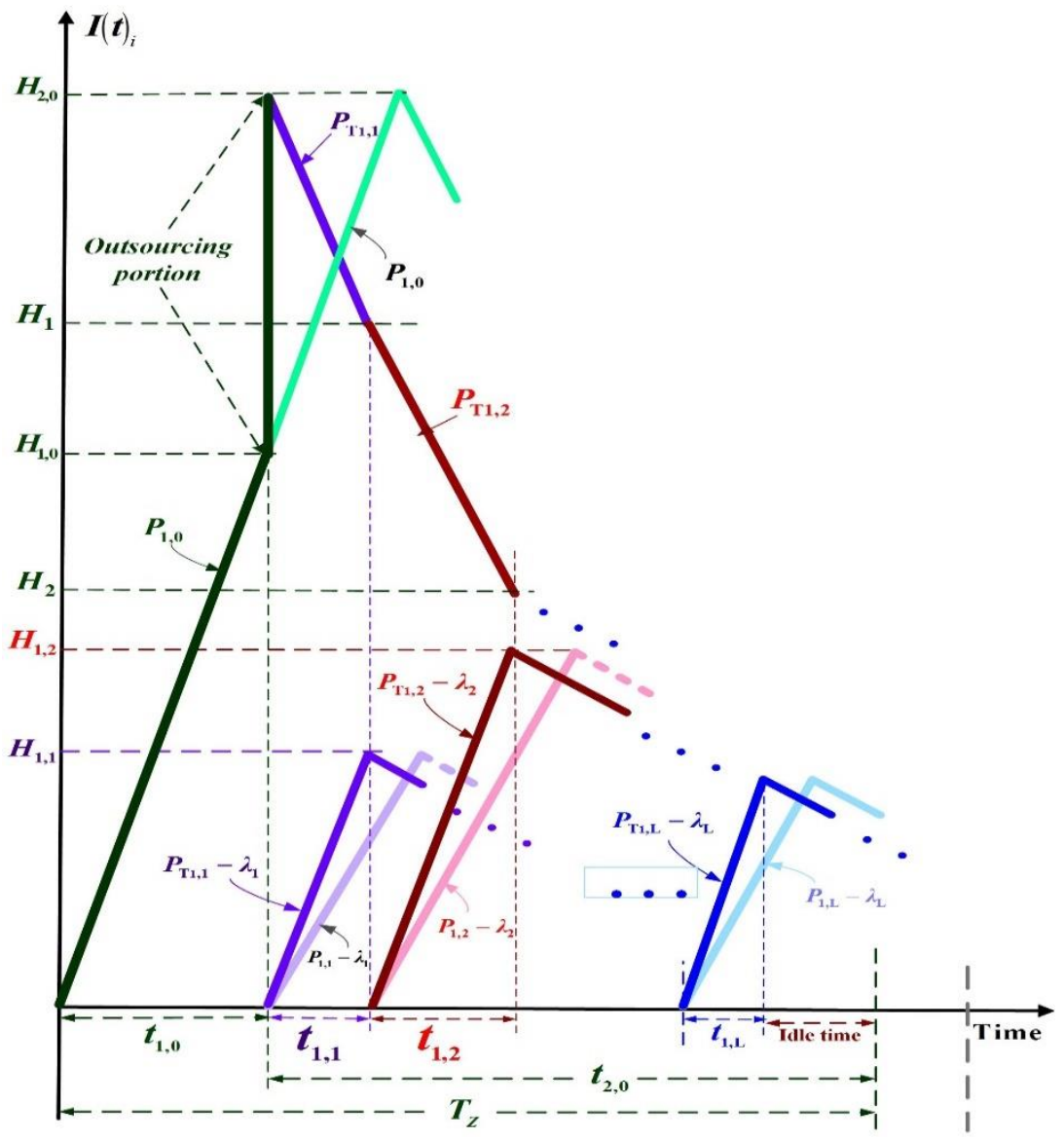

Figure 1. Stock status of the proposed single-machine two-stage multi-item production problem featuring postponement, an external source for common parts, and an adjustable-rate for end products, compared to the model without external source nor adjustable-rate. 
International Journal of Mathematical, Engineering and Management Sciences

Vol. 6, No. 3, 787-804, 2021

https://doi.org/10.33889/IJMEMS.2021.6.3.047

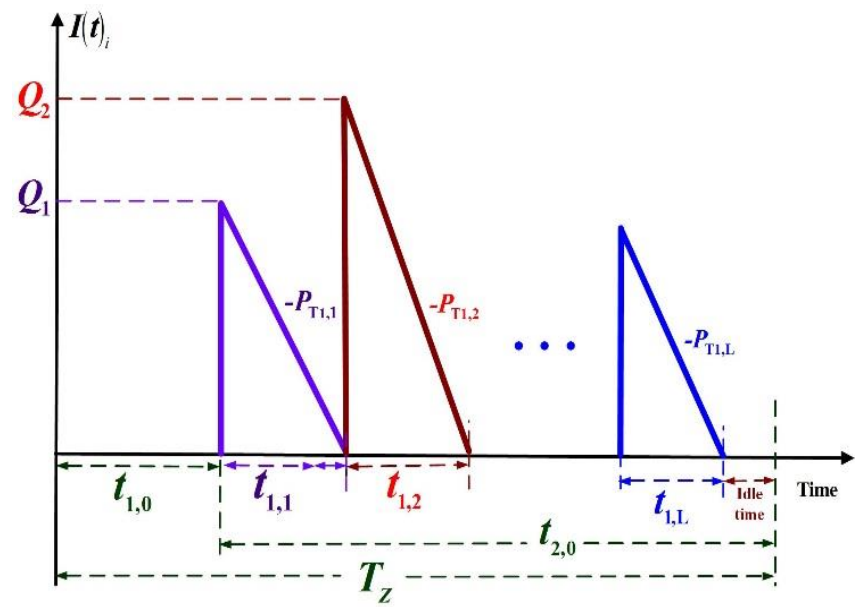

Figure 2. Common part's status in stage two of the proposed multi-item lot-sizing model.

$$
\begin{aligned}
& H_{2,0}=\sum_{i=1}^{L} Q_{i}=\sum_{i=1}^{L} \lambda_{i} T_{Z} \\
& H_{1}=H_{2,0}-Q_{1} \\
& H_{i}=H_{(i-1)}-Q_{i}, \text { for } i=2,3, \ldots, L \\
& H_{L}=H_{(L-1)}-Q_{L}=0
\end{aligned}
$$

By observing Figure 1, we can also straightforwardly gain the following formulas concerning stage one:

$$
\begin{aligned}
\lambda_{0} & =\frac{\sum_{i=1}^{L} Q_{i}}{T_{Z}} \\
Q_{0} & =H_{1,0}=\left(1-\pi_{0}\right) H_{2,0}=\left(1-\pi_{0}\right)\left(\sum_{i=1}^{L} Q_{i}\right) \\
t_{1,0} & =\frac{Q_{0}}{P_{1,0}} \\
H_{1,0} & =P_{1,0} \cdot t_{1,0}
\end{aligned}
$$

Since shortages are not allowed in this study, hence, $\left(P_{\mathrm{T} 1, i}-\lambda_{i}\right)>0$ must hold. The total productioninventory expense per cycle $T C\left(T_{\mathrm{Z}}\right)$ consists of the following costs incurred (1) stage one's outsourcing variable and setup costs and in-house production and stockholding costs; (2) in stage two, the sum of variable, setup, stockholding of scrap and safety items, and disposal costs. Therefore, $T C\left(T_{\mathrm{Z}}\right)$ is: 


$$
\begin{gathered}
T C\left(T_{Z}\right)=\pi_{0}\left(\sum_{i=1}^{L} Q_{i}\right) C_{\pi 0}+K_{\pi 0}+C_{0} Q_{0}+K_{0}+h_{1,0}\left[\frac{H_{1,0} t_{1,0}}{2}+\sum_{i=1}^{L}\left[\frac{Q_{i}}{2}\left(t_{1, i}\right)+H_{i}\left(t_{1, i}\right)\right]\right]+ \\
\sum_{i=1}^{L}\left[Q_{i} C_{T, i}+K_{T, i}+h_{1, i}\left(\frac{H_{1, i} t_{1, i}}{2}+\frac{H_{1, i} t_{2, i}}{2}\right)\right]
\end{gathered}
$$

Substitute Eqs. (1) to (18) in Eq. (19), apply $\left.T C\left(T_{\mathrm{Z}}\right)\right] / T_{\mathrm{Z}}$, and, $T C U\left(T_{\mathrm{Z}}\right)$ is gained with extra derivation as shown below:

$$
\begin{gathered}
\operatorname{TCU}\left(T_{Z}\right)=\left\{\begin{array}{c}
\frac{\left(1+\beta_{1,0}\right) K_{0}}{T_{Z}}+\left(1+\beta_{2,0}\right) C_{0} \pi_{0} \lambda_{0}+C_{0}\left(1-\pi_{0}\right) \lambda_{0}+\frac{K_{0}}{T_{Z}}+\frac{h_{1,0} \lambda_{0}{ }^{2}\left(1-\pi_{0}\right)^{2} T_{Z}}{2 P_{1,0}} \\
+h_{1,0} \sum_{i=1}^{L}\left\{\frac{\lambda_{i}^{2} T_{Z}}{2\left(1+\alpha_{1, i}\right) P_{1, i}}+\frac{\lambda_{i}}{\left(1+\alpha_{1, i}\right) P_{1, i}}\left(\sum_{i=1}^{L} \lambda_{i} T_{Z}-\sum_{j=1}^{i} \lambda_{j} T_{Z}\right)\right\}
\end{array}\right\}+ \\
\sum_{i=1}^{L}\left\{\left(1+\alpha_{3, i}\right) C_{i} \lambda_{i}+\frac{\left(1+\alpha_{2, i}\right) K_{i}}{T_{Z}}+\frac{h_{1, i} \lambda_{i}{ }^{2}}{2}\left[\frac{1}{\lambda_{i}}-\frac{1}{\left(1+\alpha_{1, i}\right) P_{1, i}}\right] T_{Z}\right\}
\end{gathered}
$$

To derive the optimal $T_{\mathrm{Z}}^{*}$, the first- and second-derivative to $T C U\left(T_{\mathrm{Z}}\right)$ are applied and the result as follows:

$$
\begin{aligned}
& \frac{d \operatorname{TCU}\left(T_{Z}\right)}{d\left(T_{Z}\right)}=\left\{-\frac{\left(1+\beta_{1,0}\right) K_{0}}{T_{Z}{ }^{2}}-\frac{K_{0}}{T_{Z}{ }^{2}}+\frac{h_{1,0} \lambda_{0}{ }^{2}\left(1-\pi_{0}\right)^{2}}{2 P_{1,0}}+h_{1,0} \sum_{i=1}^{L}\left\{\frac{\lambda_{i}{ }^{2}}{2\left(1+\alpha_{1, i}\right) P_{1, i}}\right\}+\right. \\
& \left.h_{1,0} \sum_{i=1}^{L}\left\{\frac{\lambda_{i}}{\left(1+\alpha_{1, i}\right) P_{1, i}}\left(\sum_{i=1}^{L} \lambda_{i}-\sum_{j=1}^{i} \lambda_{j}\right)\right\}\right\}+\sum_{i=1}^{L}\left\{-\frac{\left(1+\alpha_{2, i}\right) K_{i}}{T_{Z}{ }^{2}}+\frac{h_{1, i} \lambda_{i}^{2}}{2}\left[\frac{1}{\lambda_{i}}-\frac{1}{\left(1+\alpha_{1, i}\right) P_{1, i}}\right]\right\} \\
& \frac{d^{2} \operatorname{TCU}\left(T_{Z}\right)}{d\left(T_{Z}\right)^{2}}=\frac{2\left[\left(1+\beta_{1,0}\right) K_{0}\right]}{T_{Z}{ }^{3}}+\frac{2 K_{0}}{T_{Z}{ }^{3}}+\sum_{i=1}^{L} \frac{2\left[\left(1+\alpha_{2, i}\right) K_{i}\right]}{T_{Z}{ }^{3}}>0
\end{aligned}
$$

In Eq. (22), since variables $\beta_{1,0}, \alpha_{2, i}, T_{Z}, K_{0}$, and $K_{i}$ are all positive; hence, $T C U\left(T_{\mathrm{Z}}\right)$ is convex. We derive the optimal $T_{\mathrm{Z}}$ *y setting the first derivative of $T C U\left(T_{\mathrm{Z}}\right)=0$ (i.e., Eq. $(21)=0$ ).

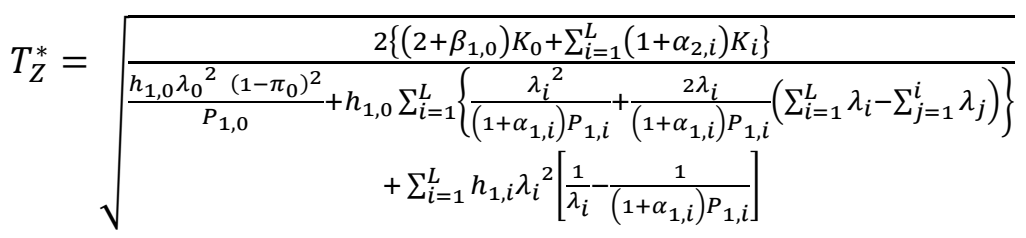

\subsection{Discussion on Setup Times and Prerequisite Condition}

We may require to calculate $T_{\min }$ (Nahmias, 2009) if the sum of setup times $S_{\mathrm{i}}$ is larger than the idle-time of the cycle (see Fig. 1). In this case, the final optimal cycle time solution is the maximum $\left(T_{\mathrm{Z}}^{*}, T_{\min }\right)$.

$$
T_{\min }=\frac{\sum_{i=0}^{L}\left(S_{i}\right)}{1-\left[\frac{\left(1-\pi_{0}\right) \lambda_{0}}{P_{1,0}}+\sum_{i=1}^{L}\left(\frac{\lambda_{i}}{P_{T 1, i}}\right)\right]}
$$


International Journal of Mathematical, Engineering and Management Sciences

Vol. 6, No. 3, 787-804, 2021

https://doi.org/10.33889/IJMEMS.2021.6.3.047

Moreover, the machine in our model must have adequate capacity to manufacture the common parts and multiple end products (Nahmias, 2009). Hence, the following prerequisite formulas must hold:

$$
\left(t_{1,0}+\sum_{i=1}^{L} t_{1, i}\right)<T_{Z} \quad \text { or } \quad\left(\frac{Q_{0}}{P_{1,0}}+\sum_{i=1}^{L} \frac{Q_{i}}{P_{T 1, i}}\right)<T_{Z} \quad \text { or }\left[\frac{\left(1-\pi_{0}\right) \lambda_{0}}{P_{1,0}}+\sum_{i=1}^{L} \frac{\lambda_{i}}{P_{T 1, i}}\right]<1
$$

\section{Numerical Illustration}

Assume variables' values exhibited in Tables 1 and 2 below are for a multi-item batch production plan featuring postponement, external source for common parts, and expedited rate for manufacturing multiproduct. Conversely, the parameters' values assumed for a single-stage production scheme of the same problem are provided in Table 3.

Table 1. The variables' values assumed in stage one.

\begin{tabular}{|c|c|c|c|c|c|c|c|c|c|c|}
\hline $\boldsymbol{\pi}_{\mathbf{0}}$ & $\boldsymbol{\beta}_{\mathbf{1 , 0}}$ & $\boldsymbol{\gamma}$ & $\boldsymbol{P}_{\mathbf{1 , 0}}$ & $\boldsymbol{\beta}_{\mathbf{2 , 0}}$ & $\boldsymbol{\lambda}_{\mathbf{0}}$ & $\boldsymbol{\delta}$ & $\boldsymbol{C}_{\mathbf{0}}$ & $\boldsymbol{h}_{\mathbf{1 , 0}}$ & $\boldsymbol{K}_{\mathbf{0}}$ & $\mathbf{i}_{\mathbf{0}}$ \\
\hline 0.4 & -0.7 & 0.5 & 120000 & 0.4 & 17000 & 0.5 & $\$ 40$ & $\$ 8$ & $\$ 8500$ & 0.2 \\
\hline
\end{tabular}

Table 2. The variables' values assumed in stage two.

\begin{tabular}{|c|c|c|c|c|c|c|c|c|c|}
\hline Product $\boldsymbol{i}$ & $\boldsymbol{\alpha}_{\mathbf{1}, \boldsymbol{i}}$ & $\boldsymbol{C}_{\boldsymbol{i}}$ & $\boldsymbol{\alpha}_{\mathbf{2}, \boldsymbol{i}}$ & $\boldsymbol{\lambda}_{\boldsymbol{i}}$ & $\boldsymbol{\alpha}_{\mathbf{3}, \boldsymbol{i}}$ & $\boldsymbol{i}_{\boldsymbol{i}}$ & $\boldsymbol{K}_{\boldsymbol{i}}$ & $\boldsymbol{P}_{\mathbf{1}, i}$ & $\boldsymbol{h}_{\mathbf{1}, \boldsymbol{i}}$ \\
\hline 1 & 0.5 & $\$ 40$ & 0.1 & 3000 & 0.25 & 0.2 & $\$ 8500$ & 112258 & $\$ 16$ \\
\hline 2 & 0.5 & $\$ 50$ & 0.1 & 3200 & 0.25 & 0.2 & $\$ 9000$ & 116066 & $\$ 18$ \\
\hline 3 & 0.5 & $\$ 60$ & 0.1 & 3400 & 0.25 & 0.2 & $\$ 9500$ & 120000 & $\$ 20$ \\
\hline 4 & 0.5 & $\$ 70$ & 0.1 & 3600 & 0.25 & 0.2 & $\$ 10000$ & 124068 & $\$ 22$ \\
\hline 5 & 0.5 & $\$ 80$ & 0.1 & 3800 & 0.25 & 0.2 & $\$ 10500$ & 128276 & $\$ 24$ \\
\hline
\end{tabular}

Table 3. The variables' values assumed in a single-stage scheme of the same problem.

\begin{tabular}{|c|c|c|c|c|c|c|}
\hline Product $\boldsymbol{i}$ & $\boldsymbol{C}_{\boldsymbol{i}}$ & $\boldsymbol{i}$ & $\boldsymbol{P}_{\mathbf{1}, \boldsymbol{i}}$ & $\boldsymbol{h}_{\mathbf{1}, \boldsymbol{i}}$ & $\boldsymbol{\lambda}_{\boldsymbol{i}}$ & $\boldsymbol{K}_{\boldsymbol{i}}$ \\
\hline 1 & $\$ 80$ & 0.2 & 58000 & $\$ 16$ & 3000 & $\$ 17000$ \\
\hline 2 & $\$ 90$ & 0.2 & 59000 & $\$ 18$ & 3200 & $\$ 17500$ \\
\hline 3 & $\$ 100$ & 0.2 & 60000 & $\$ 20$ & 3400 & $\$ 18000$ \\
\hline 4 & $\$ 110$ & 0.2 & 61000 & $\$ 22$ & 3600 & $\$ 18500$ \\
\hline 5 & $\$ 120$ & 0.2 & 62000 & $\$ 24$ & 3800 & $\$ 19000$ \\
\hline
\end{tabular}

Through calculating formulas (23) and (20), we find $T_{\mathrm{Z}} *=0.5950$ years and $E\left[T C U\left(T_{\mathrm{Z}} *\right)\right]=$ $\$ 2,301,559$ for the studied multi-item production lot sizing problem containing postponement, external source for common parts, and adjustable-rate for end products fabrication.

\subsection{The Collective Influence of Diverse Features on the Problem}

The analytical outcomes of the collective influence of cycle time $T_{Z}$ and the adjustable-rate factor $\alpha_{1, i}$ on $E\left[T C U\left(T_{\mathrm{Z}}\right)\right]$ are exhibited in Figure 3. It exhibits as $T_{\mathrm{Z}}$ deviates from $T_{\mathrm{Z}}{ }^{*}$ (which is 0.5950 ), $E\left[T C U\left(T_{\mathrm{Z}}\right)\right]$ surges in both directions. It confirms the convexity of $E\left[T C U\left(T_{\mathrm{Z}}\right)\right]$ concerning $T_{\mathrm{Z}}$ and also shows that as $\alpha_{1, i}$ increases, $E\left[T C U\left(T_{\mathrm{Z}}\right)\right]$ noticeably rises. 
International Journal of Mathematical, Engineering and Management Sciences

Vol. 6, No. 3, 787-804, 2021

https://doi.org/10.33889/IJMEMS.2021.6.3.047

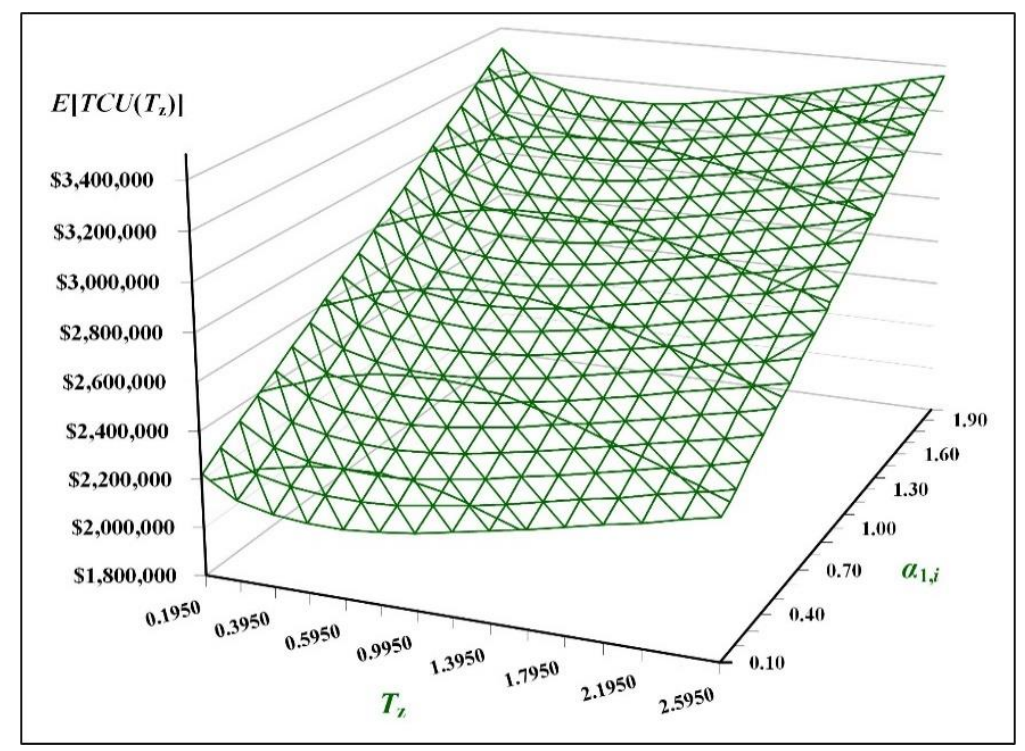

Figure 3. The analytical outcomes of the collective influence of $T_{\mathrm{Z}}$ and $\alpha_{1, i}$ on $E\left[T C U\left(T_{\mathrm{Z}}\right)\right]$.

Figure 4 exhibits the combined impact of the adjustable-rate and outsourcing factors (i.e., $\alpha_{1, i}$ and $\pi_{0}$ ) on utilization. It exposes the utilization drops severely, as $\pi_{0}$ increases; utilization decreases noticeably, as $\alpha_{1, i}$ increases.

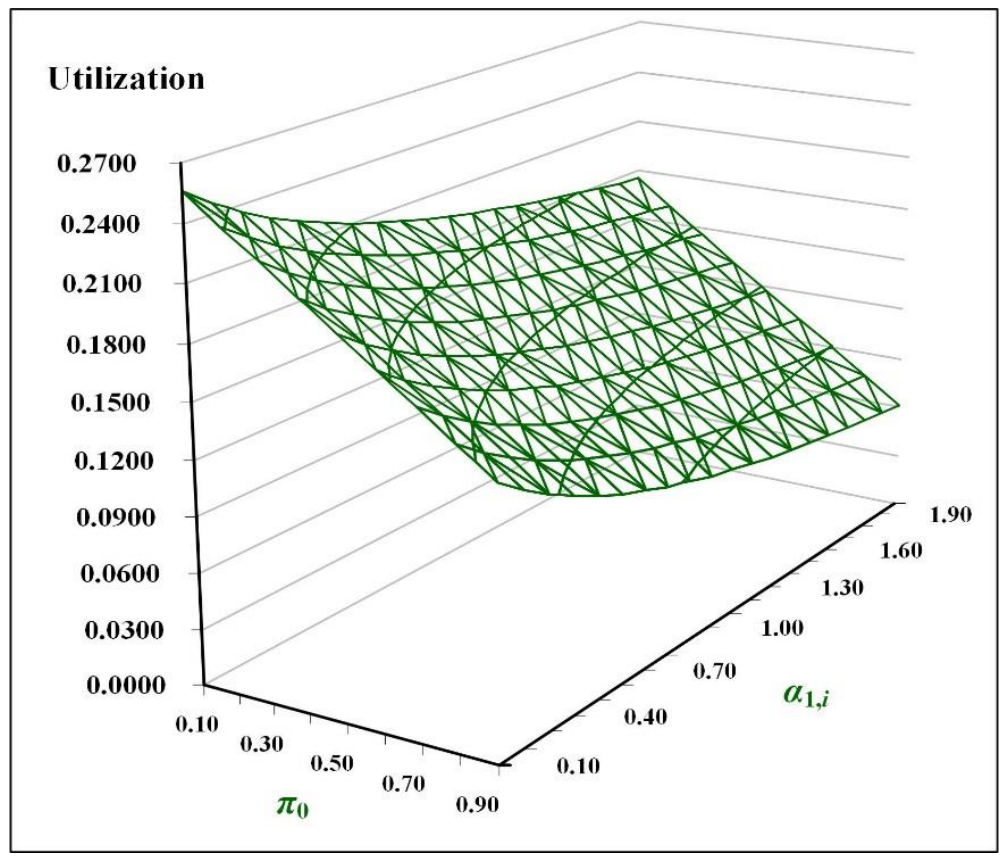

Figure 4. The combined impact of $\alpha_{1, i}$ and $\pi_{0}$ on the utilization. 
International Journal of Mathematical, Engineering and Management Sciences

Vol. 6, No. 3, 787-804, 2021

https://doi.org/10.33889/IJMEMS.2021.6.3.047

Figure 5 shows the investigative outcomes of the collective effect of $\pi_{0}$ and $\alpha_{1, i}$ on $E\left[T C U\left(T_{\mathrm{Z}}^{*}\right)\right]$. It exposes as both $\pi_{0}$ and $\alpha_{1, i}$ increase, $E\left[T C U\left(T_{\mathrm{Z}}{ }^{*}\right)\right]$ rises considerably. It discovers that in our example, $\alpha_{1, i}$ has more impact $\pi_{0}$ on $E\left[T C U\left(T_{\mathrm{Z}}{ }^{*}\right)\right]$ increase.

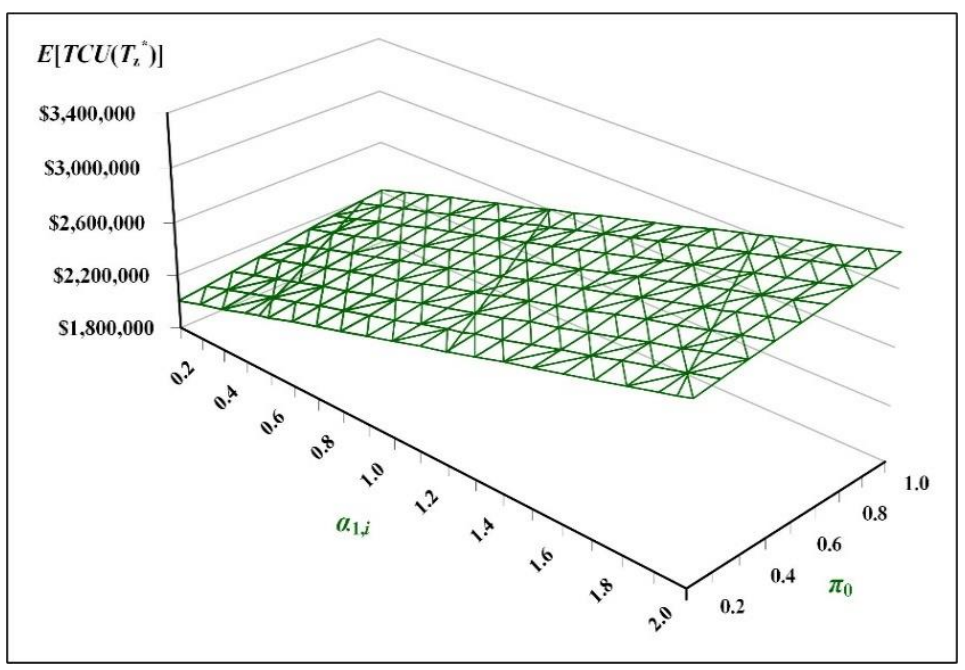

Figure 5. The collective effect of $\pi_{0}$ and $\alpha_{1, i}$ on $E\left[T C U\left(T_{Z}^{*}\right)\right]$.

\subsection{The Effect of the Dual Uptime-Reduction Strategies on the Proposed Study}

This study proposes dual uptime-reduction strategies (i.e., outsourcing the common parts and the adjustable-rate for fabricating end products. The individual effect of these strategies on the proposed study is explicitly investigated below. Figure 6 displays the investigative outcome of the changes in the sum of end products' uptimes $t_{i}{ }^{*}$ concerning $\alpha_{1, i}$. It exposes that the sum of end products' uptimes $t_{i}^{*}$ declines $30.36 \%$ at $\alpha_{1, i}=0.5$ (i.e., it drops from 0.0805 years to 0.0560 ). We are paying an increase of $13.13 \%$ in $E\left[T C U\left(T_{\mathrm{Z}}{ }^{*}\right)\right]$ when reducing a $30.36 \%$ in $t_{i}^{*}$ (please see Table A-1 in Appendix A for details).

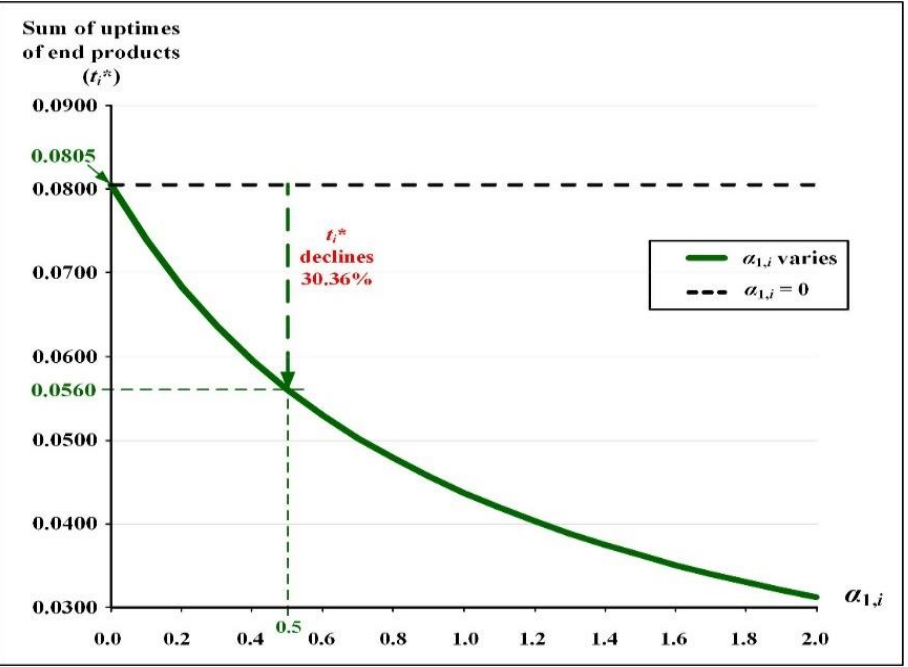

Figure 6. The changes in the sum of end products' uptimes concerning $\alpha_{1, i \text {. }}$ 
International Journal of Mathematical, Engineering and Management Sciences

Vol. 6, No. 3, 787-804, 2021

https://doi.org/10.33889/IJMEMS.2021.6.3.047

Figure 7 exhibits the investigative outcomes of optimal uptime $t_{0} *$ concerning the outsourcing proportion $\pi_{0}$. It discovers when $\pi_{0}=0.4$, the optimal uptime $t_{0} *$ declines a $37.71 \%$. That is, $t_{0} *$ decreases from 0.0812 years to 0.0506 years (for details, see Table A-2 in Appendix A).

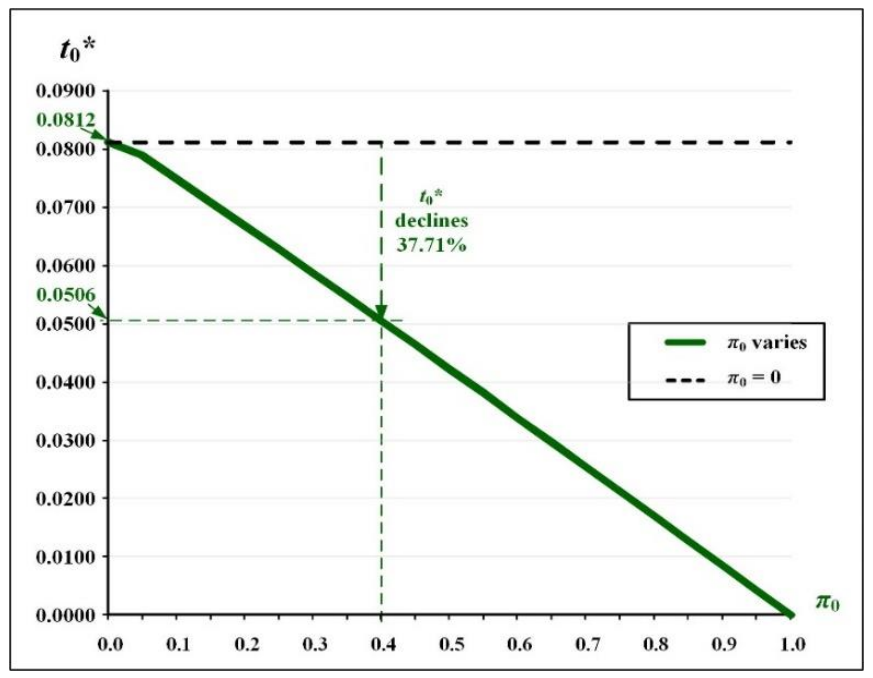

Figure 7. The differences in uptime $t_{0} *$ concerning the outsourcing proportion $\pi_{0}$.

Figure 8 depicts the analytical results of $E\left[T C U\left(T_{\mathrm{Z}}{ }^{*}\right)\right]$ and its contributors concerning the outsourcing proportion $\pi_{0}$. It discloses that as $\pi_{0}$ increases, the outsourcing expenses upsurges significantly, but the common parts' in-house variable costs decline considerably. All other contributors to $E\left[T C U\left(T_{\mathrm{Z}}{ }^{*}\right)\right]$ have insignificant effect relating to $\pi_{0}$. At $\pi_{0}=0.4$, we pay a price of $5.00 \%$ more in $E\left[T C U\left(T_{\mathrm{Z}}^{*}\right)\right]$ for reducing $t_{0}^{*}$ by $37.71 \%$. Specifically, $E\left[T C U\left(T_{\mathrm{Z}}^{*}\right)\right]$ surges from $\$ 2,191,993$ to $\$ 2,301,559$ (for details, see Table A-2 in Appendix A).

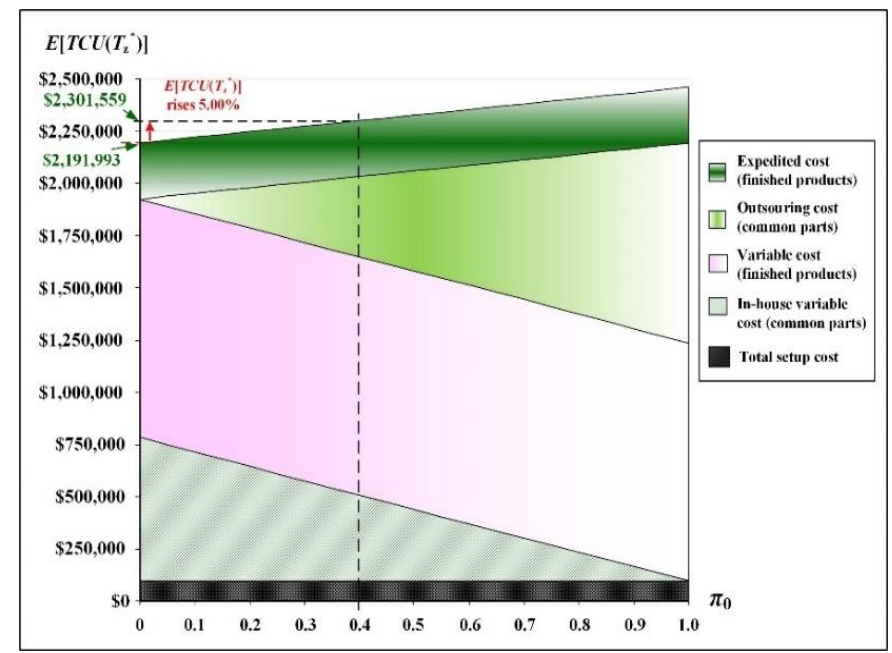

Figure 8. The variations in $E\left[T C U\left(T_{Z}^{*}\right)\right]$ and its contributors concerning $\pi_{0}$. 
Figure 9 explicitly investigates and illustrates the distinct and joint influence of $\alpha_{1, i}$ and $\pi_{0}$ on $E\left[T C U\left(T_{\mathrm{Z}}^{*}\right)\right]$. Our numerical example indicates that to effectively shorten the manufacturing uptime/ utilization, it is more cost-effective to implement $\pi_{0}=40 \%$ in the fabrication stage one. To further reduce the utilization, the more economical strategy is to gradually implement the adjustable-rate $\alpha_{1, i}$ in stage two. When $\alpha_{1, i}$ reaches 0.5 and $\pi_{0}$ remains at 0.4 , to cut utilization, further, a cost-effective approach is to let $\alpha_{1, i}$ remain at 0.5 and start to increase $\pi_{0}$ solely. One thing worth to mention is that the proposed model can perform a similar study for any given parameters' values and discovers crucial in-depth information to support managerial decision-making. For example, $\pi_{0}=0.5$ can be justified as a better starting point than $\pi_{0}=0.4$, in terms of a more economical alternative in reducing utilization.

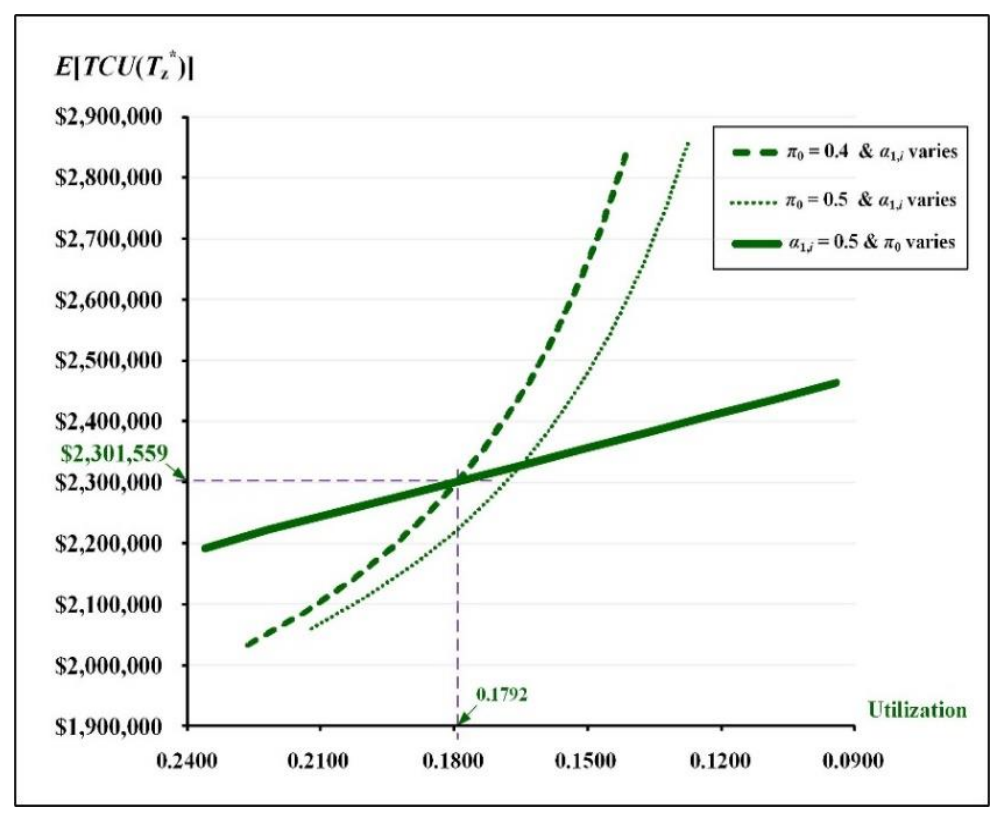

Figure 9. The distinct and collective influence of $\alpha_{1, i}$ and $\pi_{0}$ on $E\left[T C U\left(T_{\mathrm{Z}}{ }^{*}\right)\right]$.

\subsection{Comparisons with Various Closely Related Models}

Figure 10 demonstrates the comparisons of our study's utilization with diverse, closely related models. Our model results in the lowest utilization (i.e., 0.1792) by implementing both outsourcing and adjustable-rate strategies. It is $20.81 \%$ lower than a similar model with only outsourcing strategy (Chiu et al., 2020b), and our utilization is $36.66 \%$ lower than a model without neither outsourcing nor adjustable-rate strategies. 
International Journal of Mathematical, Engineering and Management Sciences

Vol. 6, No. 3, 787-804, 2021

https://doi.org/10.33889/IJMEMS.2021.6.3.047

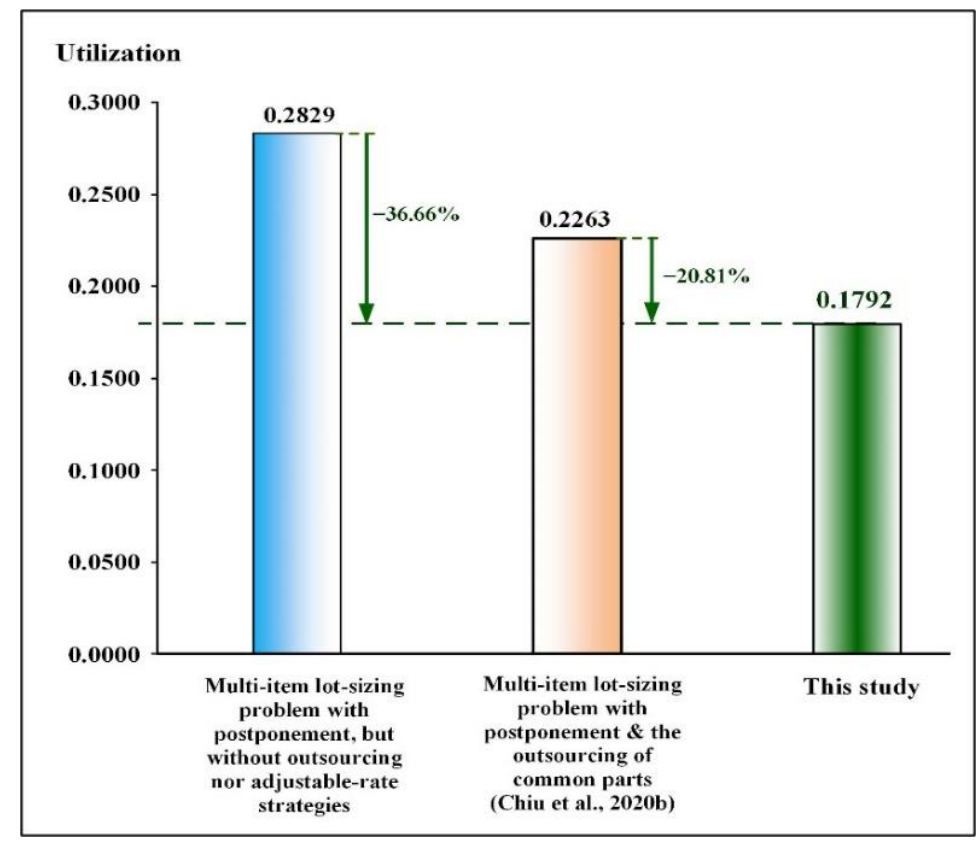

Figure 10. The comparison of our study's utilization with various closely related models.

Figure 11 exhibits our study's $E\left[T C U\left(T_{\mathrm{Z}}^{*}\right)\right]$ with various closely related models. It exposes that we pay a price of $13.13 \%$ or $19.60 \%$ rise in $E\left[T C U\left(T_{\mathrm{Z}}^{*}\right)\right]$ to reduce utilization by $20.81 \%$ or $36.66 \%$ compared to various related models. Our study reveals such critical information to managers to facilitate their fabrication decision-makings.

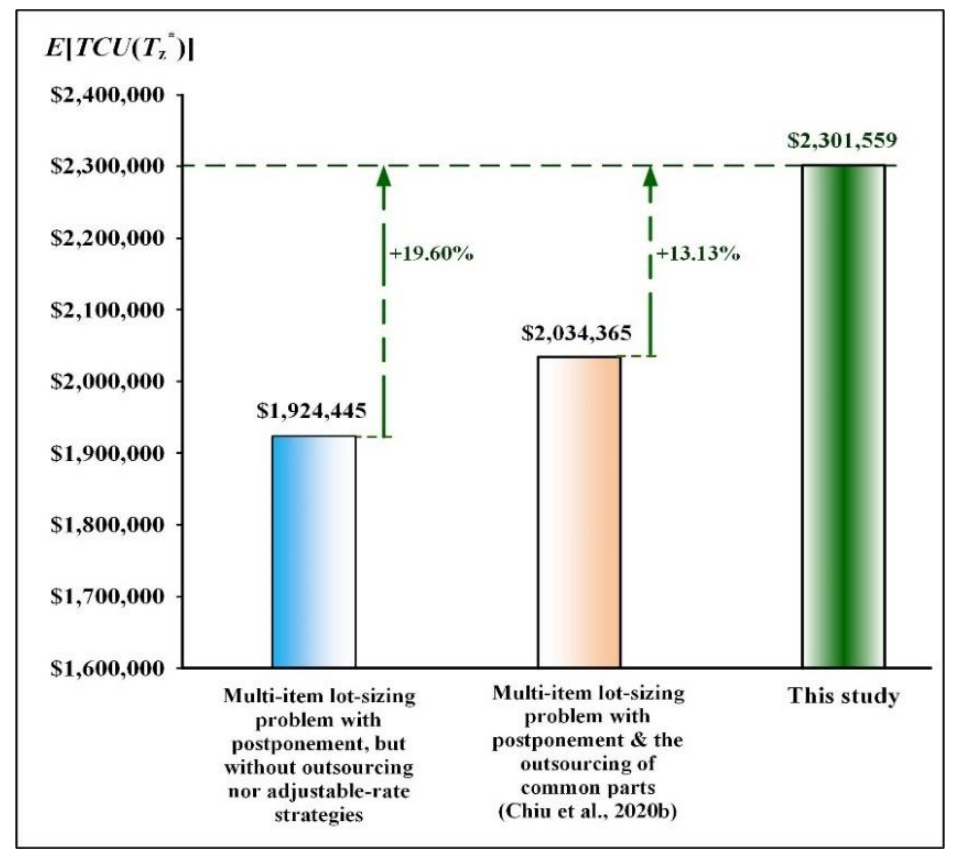

Figure 11. The comparison of our study's $E\left[T C U\left(T_{\mathrm{Z}}^{*}\right)\right]$ with various closely related models. 
International Journal of Mathematical, Engineering and Management Sciences

Vol. 6, No. 3, 787-804, 2021

https://doi.org/10.33889/IJMEMS.2021.6.3.047

\subsection{Other Analytical Capabilities of the Proposed Model}

Furthermore, Figure 12 exhibits the cost contributors to $E\left[T C U\left(T_{Z}^{*}\right)\right]$. It exposes ng end products; please (see Tables A-1 and A-2 for details). The cost related to adjustable-rate for end products and outsourcing common parts contributes $11.64 \%$ and $16.73 \%$ of $E\left[T C U\left(T_{Z}^{*}\right)\right]$. The relevant in-house variable costs for end products and common parts contribute $49.55 \%$ and $17.99 \%$ each.

Moreover, Figure 13 depicts the impact of the nonlinear (e.g., $\delta=\gamma^{3}$ ) and linear (i.e., $\delta=\gamma^{1}$ ) relationships between $\delta$ and $\gamma$ on $T_{\mathrm{Z}}{ }^{*}$. It not only confirms that our example's at $\gamma=0.50, T_{\mathrm{Z}}{ }^{*}=$ 0.5950 (see Table A-2), but also discovers the critical information of $T_{\mathrm{Z}}^{*}$ changes relating to the nonlinear relationships between $\delta$ and $\gamma$ (e.g., $\left.\delta=\gamma^{3}\right)$.

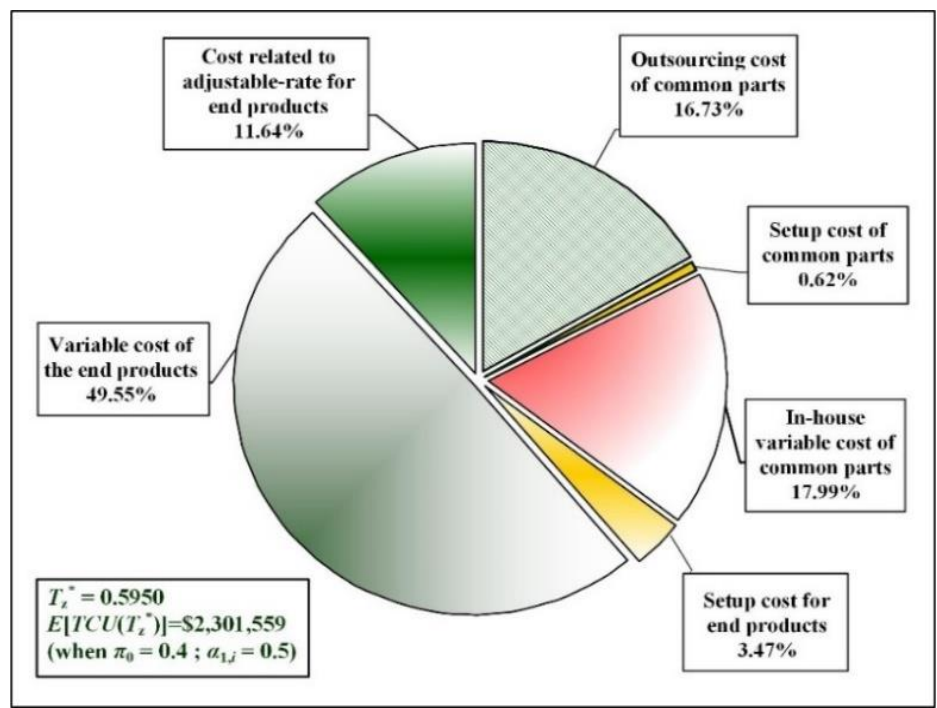

Figure 12. Different cost contributors to $E\left[T C U\left(T_{\mathrm{Z}}{ }^{*}\right)\right]$.

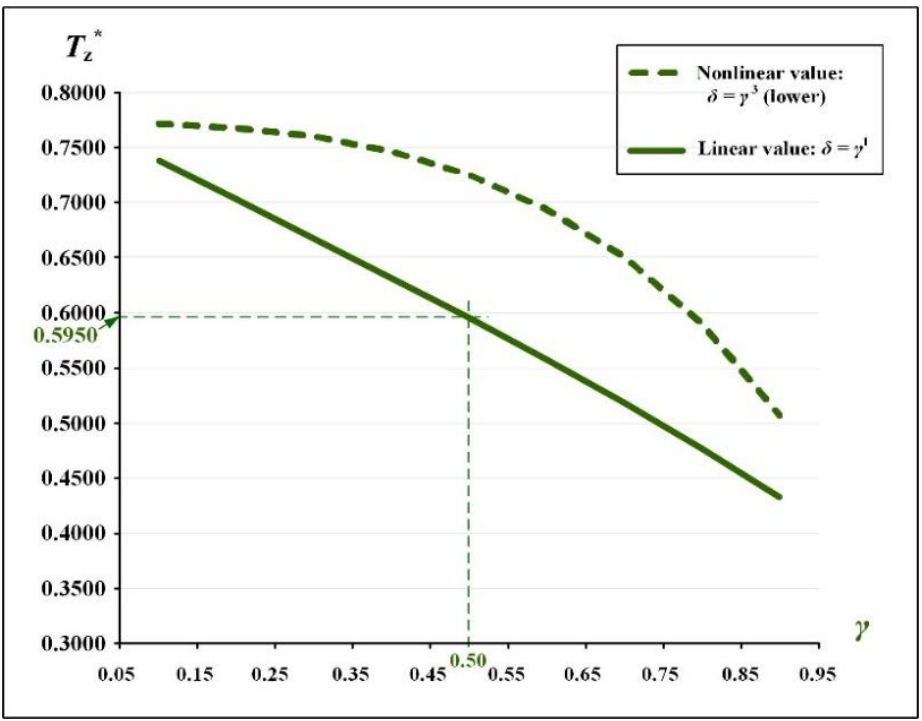

Figure 13. The effect of the nonlinear/linear relationships between $\delta$ and $\gamma$ on $T_{\mathrm{Z}}{ }^{*}$. 
International Journal of Mathematical, Engineering and Management Sciences

Vol. 6, No. 3, 787-804, 2021

https://doi.org/10.33889/IJMEMS.2021.6.3.047

\section{Conclusions}

This work investigates a multi-item production lot-size problem incorporating postponement, the external source for common parts, and adjustable-rate for end products. We proposed a two-stage postponement scheme and built a model to explicitly characterize the problem's features, including an external common-part source and an end-product adjustable rate. The objective is to help managers make a cost-effective lot-size decision and allow manufacturers to gain competitive advantages. We use the mathematical analysis and optimization methods to prove the problem's total cost function's convexity and derive the optimal rotation cycle time (see Section two). A numerical illustration is used to validate the obtained result's capability and applicability. It reveals the combined/individual impact of variations in cycle length, outsourcing portion, common part's completion rate, and expedited-rate factor on the total fabrication related expenses, utilization, end product's variable cost, different cost contributors, and uptimes of stage one and stage two (refer to Figures 4 to 9, and 12). We further compare our study's utilization and system's cost with closely relating problems (refer to Figures 10 to 11). Furthermore, the nonlinear and linear relationships between the common part's value and completion rate are investigated (see Figure 13). Main contributions of this study include (1) A decision-support model is now available to explore this particular problem and determine the optimal rotation cycle. (2) The collective and individual influence of dual uptime-reduction strategies on the problem's operating policy and various performance indexes is revealed to facilitate managerial decision-making. For future work, combining the product quality relevant matters into the problem is a worth-investigated topic.

\section{Conflict of Interest}

The authors confirm that there is no conflict of interest to declare for this publication.

\section{Acknowledgments}

The authors appreciate the Ministry of Science and Technology of Taiwan for supporting this work (No. MOST 1092221-E-324-015).

\section{Appendix - A}

Table A-1. The influence of differences in adjustable-rate factor $\alpha_{1,0}$ on different system parameters.

\begin{tabular}{|c|c|c|c|c|c|c|c|c|c|c|c|}
\hline$\alpha_{1,0}$ & $\begin{array}{c}\mathrm{E}\left[T C U\left(\mathrm{Z}^{*}\right)\right] \\
(\mathrm{A})\end{array}$ & $\begin{array}{c}\mathrm{A}) \% \\
\text { increase }\end{array}$ & $\alpha_{2,0}$ & $T_{\mathrm{Z}} *$ & $\alpha_{3,0}$ & $t_{\mathrm{i}}{ }^{*}$ & $\begin{array}{c}t_{\mathrm{i}}{ }^{*} \\
\text { decline } \\
\%\end{array}$ & $\begin{array}{c}\text { Utilization } \\
(\mathrm{B})\end{array}$ & $\begin{array}{c}\text { Extra cost } \\
(\mathrm{B}) \% \\
\text { decline }\end{array}$ & $\begin{array}{c}\text { due to the } \\
\text { adjustble- } \\
\text { rate }(\mathrm{C})\end{array}$ & $\begin{array}{c}(\mathrm{C}) /(\mathrm{A}) \\
\%\end{array}$ \\
\hline 0.0 & $\$ 2,034,365$ & - & 0.00 & 0.5696 & 0.00 & 0.0805 & - & 0.2263 & - & $\$ 0$ & $0.00 \%$ \\
\hline 0.1 & $\$ 2,087,767$ & $2.62 \%$ & 0.02 & 0.5750 & 0.05 & 0.0738 & $-8.24 \%$ & 0.2134 & $-5.68 \%$ & $\$ 53,652$ & $2.57 \%$ \\
\hline 0.2 & $\$ 2,141,194$ & $5.25 \%$ & 0.04 & 0.5802 & 0.10 & 0.0683 & $-15.13 \%$ & 0.2027 & $-10.41 \%$ & $\$ 107,275$ & $5.01 \%$ \\
\hline 0.3 & $\$ 2,194,639$ & $7.88 \%$ & 0.06 & 0.5852 & 0.15 & 0.0636 & $-20.98 \%$ & 0.1937 & $-14.41 \%$ & $\$ 160,870$ & $7.33 \%$ \\
\hline 0.4 & $\$ 2,248,096$ & $10.51 \%$ & 0.08 & 0.5902 & 0.20 & 0.0596 & $-26.00 \%$ & 0.1859 & $-17.84 \%$ & $\$ 214,439$ & $9.54 \%$ \\
\hline $\mathbf{0 . 5}$ & $\mathbf{\$ 2 , 3 0 1 , 5 5 9}$ & $\mathbf{1 3 . 1 3 \%}$ & $\mathbf{0 . 1 0}$ & $\mathbf{0 . 5 9 5 0}$ & $\mathbf{0 . 2 5}$ & $\mathbf{0 . 0 5 6 0}$ & $\mathbf{- 3 0 . 3 6 \%}$ & $\mathbf{0 . 1 7 9 2}$ & $\mathbf{- 2 0 . 8 1 \%}$ & $\mathbf{\$ 2 6 7 , 9 8 3}$ & $\mathbf{1 1 . 6 4 \%}$ \\
\hline 0.6 & $\$ 2,355,025$ & $15.76 \%$ & 0.12 & 0.5998 & 0.30 & 0.0530 & $-34.19 \%$ & 0.1733 & $-23.41 \%$ & $\$ 321,503$ & $13.65 \%$ \\
\hline 0.7 & $\$ 2,408,493$ & $18.39 \%$ & 0.14 & 0.6046 & 0.35 & 0.0502 & $-37.57 \%$ & 0.1681 & $-25.71 \%$ & $\$ 375,000$ & $15.57 \%$ \\
\hline 0.8 & $\$ 2,461,960$ & $21.02 \%$ & 0.16 & 0.6092 & 0.40 & 0.0478 & $-40.58 \%$ & 0.1635 & $-27.75 \%$ & $\$ 428,475$ & $17.40 \%$ \\
\hline 0.9 & $\$ 2,515,425$ & $23.65 \%$ & 0.18 & 0.6138 & 0.45 & 0.0456 & $-43.29 \%$ & 0.1594 & $-29.57 \%$ & $\$ 481,929$ & $19.16 \%$ \\
\hline 1.0 & $\$ 2,568,886$ & $26.27 \%$ & 0.20 & 0.6184 & 0.50 & 0.0437 & $-45.72 \%$ & 0.1556 & $-31.22 \%$ & $\$ 535,362$ & $20.84 \%$ \\
\hline 1.1 & $\$ 2,622,343$ & $28.90 \%$ & 0.22 & 0.6229 & 0.55 & 0.0419 & $-47.93 \%$ & 0.1523 & $-32.70 \%$ & $\$ 588,776$ & $22.45 \%$ \\
\hline
\end{tabular}


International Journal of Mathematical, Engineering and Management Sciences

Vol. 6, No. 3, 787-804, 2021

https://doi.org/10.33889/IJMEMS.2021.6.3.047

Table A-1 continued...

\begin{tabular}{|l|l|l|l|l|l|l|l|l|l|l|l|}
\hline 1.2 & $\$ 2,675,796$ & $31.53 \%$ & 0.24 & 0.6274 & 0.60 & 0.0403 & $-49.94 \%$ & 0.1492 & $-34.05 \%$ & $\$ 642,171$ & $24.00 \%$ \\
\hline 1.3 & $\$ 2,729,243$ & $34.16 \%$ & 0.26 & 0.6318 & 0.65 & 0.0388 & $-51.78 \%$ & 0.1464 & $-35.29 \%$ & $\$ 695,548$ & $25.49 \%$ \\
\hline 1.4 & $\$ 2,782,685$ & $36.78 \%$ & 0.28 & 0.6362 & 0.70 & 0.0374 & $-53.47 \%$ & 0.1439 & $-36.42 \%$ & $\$ 748,907$ & $26.91 \%$ \\
\hline 1.5 & $\$ 2,836,120$ & $39.41 \%$ & 0.30 & 0.6405 & 0.75 & 0.0362 & $-55.02 \%$ & 0.1415 & $-37.46 \%$ & $\$ 802,248$ & $28.29 \%$ \\
\hline 1.6 & $\$ 2,889,549$ & $42.04 \%$ & 0.32 & 0.6448 & 0.80 & 0.0350 & $-56.46 \%$ & 0.1393 & $-38.42 \%$ & $\$ 855,573$ & $29.61 \%$ \\
\hline 1.7 & $\$ 2,942,972$ & $44.66 \%$ & 0.34 & 0.6491 & 0.85 & 0.0340 & $-57.80 \%$ & 0.1373 & $-39.31 \%$ & $\$ 908,881$ & $30.88 \%$ \\
\hline 1.8 & $\$ 2,996,388$ & $47.29 \%$ & 0.36 & 0.6533 & 0.90 & 0.0330 & $-59.04 \%$ & 0.1355 & $-40.14 \%$ & $\$ 962,174$ & $32.11 \%$ \\
\hline 1.9 & $\$ 3,049,797$ & $49.91 \%$ & 0.38 & 0.6575 & 0.95 & 0.0320 & $-60.20 \%$ & 0.1337 & $-40.91 \%$ & $\$ 1,015,452$ & $33.30 \%$ \\
\hline 2.0 & $\$ 3,103,200$ & $52.54 \%$ & 0.40 & 0.6617 & 1.00 & 0.0312 & $-61.28 \%$ & 0.1321 & $-41.62 \%$ & $\$ 1,068,714$ & $34.44 \%$ \\
\hline
\end{tabular}

Table A-2. The influence of differences in $\pi_{0}$ on different system parameters.

\begin{tabular}{|c|c|c|c|c|c|c|c|c|c|}
\hline$\pi_{0}$ & $T_{\mathrm{Z}}^{*}$ & $t_{0} *$ & $\begin{array}{c}t_{0}^{*} \\
\text { decline } \\
\%\end{array}$ & Utilization (A) & $\begin{array}{c}\text { (A) } \\
\text { decline } \\
\%\end{array}$ & $\begin{array}{c}\mathrm{E}\left[T C U\left(T_{\mathrm{Z}}{ }^{*}\right)\right] \\
(\mathrm{B})\end{array}$ & $\begin{array}{c}\text { (B) } \\
\text { increase } \\
\%\end{array}$ & $\begin{array}{l}\text { Additional } \\
\text { cost due to } \\
\text { outsourcing } \\
\text { (C) }\end{array}$ & $\begin{array}{c}(\mathrm{C}) /(\mathrm{B}) \\
\%\end{array}$ \\
\hline 0.00 & 0.5731 & 0.0812 & - & 0.2358 & - & $\$ 2,191,993$ & - & $\$ 0$ & $0.00 \%$ \\
\hline 0.05 & 0.5865 & 0.0789 & $-2.78 \%$ & 0.2288 & $-3.00 \%$ & $\$ 2,209,446$ & $0.80 \%$ & $\$ 51,948$ & $2.35 \%$ \\
\hline 0.10 & 0.5880 & 0.0750 & $-7.67 \%$ & 0.2217 & $-6.01 \%$ & $\$ 2,222,523$ & $1.39 \%$ & $\$ 99,537$ & $4.48 \%$ \\
\hline 0.15 & 0.5893 & 0.0710 & $-12.60 \%$ & 0.2146 & $-9.01 \%$ & $\$ 2,235,627$ & $1.99 \%$ & $\$ 147,127$ & $6.58 \%$ \\
\hline 0.20 & 0.5906 & 0.0669 & $-17.56 \%$ & 0.2075 & $-12.01 \%$ & $\$ 2,248,758$ & $2.59 \%$ & $\$ 194,718$ & $8.66 \%$ \\
\hline 0.25 & 0.5918 & 0.0629 & $-22.55 \%$ & 0.2004 & $-15.02 \%$ & $\$ 2,261,916$ & $3.19 \%$ & $\$ 242,309$ & $10.71 \%$ \\
\hline 0.30 & 0.5930 & 0.0588 & $-27.58 \%$ & 0.1933 & $-18.02 \%$ & $\$ 2,275,103$ & $3.79 \%$ & $\$ 289,900$ & $12.74 \%$ \\
\hline 0.35 & 0.5940 & 0.0547 & $-32.63 \%$ & 0.1863 & $-21.02 \%$ & $\$ 2,288,317$ & $4.39 \%$ & $\$ 337,493$ & $14.75 \%$ \\
\hline 0.40 & 0.5950 & 0.0506 & $-37.71 \%$ & 0.1792 & $-24.03 \%$ & $\$ 2,301,559$ & $5.00 \%$ & $\$ 385,085$ & $16.73 \%$ \\
\hline 0.45 & 0.5960 & 0.0464 & $-42.81 \%$ & 0.1721 & $-27.03 \%$ & $\$ 2,314,829$ & $5.60 \%$ & $\$ 432,679$ & $18.69 \%$ \\
\hline 0.50 & 0.5968 & 0.0423 & $-47.93 \%$ & 0.1650 & $-30.03 \%$ & $\$ 2,328,127$ & $6.21 \%$ & $\$ 480,273$ & $20.63 \%$ \\
\hline 0.55 & 0.5976 & 0.0381 & $-53.08 \%$ & 0.1579 & $-33.04 \%$ & $\$ 2,341,454$ & $6.82 \%$ & $\$ 527,867$ & $22.54 \%$ \\
\hline 0.60 & 0.5983 & 0.0339 & $-58.25 \%$ & 0.1508 & $-36.04 \%$ & $\$ 2,354,809$ & $7.43 \%$ & $\$ 575,462$ & $24.44 \%$ \\
\hline 0.65 & 0.5989 & 0.0297 & $-63.43 \%$ & 0.1438 & $-39.04 \%$ & $\$ 2,368,193$ & $8.04 \%$ & $\$ 623,058$ & $26.31 \%$ \\
\hline 0.70 & 0.5994 & 0.0255 & $-68.62 \%$ & 0.1367 & $-42.05 \%$ & $\$ 2,381,605$ & $8.65 \%$ & $\$ 670,654$ & $28.16 \%$ \\
\hline 0.75 & 0.5999 & 0.0212 & $-73.83 \%$ & 0.1296 & $-45.05 \%$ & $\$ 2,395,046$ & $9.26 \%$ & $\$ 718,251$ & $29.99 \%$ \\
\hline 0.80 & 0.6002 & 0.0170 & $-79.05 \%$ & 0.1225 & $-48.05 \%$ & $\$ 2,408,516$ & $9.88 \%$ & $\$ 765,848$ & $31.80 \%$ \\
\hline 0.85 & 0.6005 & 0.0128 & $-84.28 \%$ & 0.1154 & $-51.06 \%$ & $\$ 2,422,015$ & $10.49 \%$ & $\$ 813,446$ & $33.59 \%$ \\
\hline 0.90 & 0.6007 & 0.0085 & $-89.52 \%$ & 0.1083 & $-54.06 \%$ & $\$ 2,435,543$ & $11.11 \%$ & $\$ 861,045$ & $35.35 \%$ \\
\hline 0.95 & 0.6009 & 0.0043 & $-94.76 \%$ & 0.1013 & $-57.06 \%$ & $\$ 2,449,099$ & $11.73 \%$ & $\$ 908,644$ & $37.10 \%$ \\
\hline 1.00 & 0.6009 & 0.0000 & $-100.00 \%$ & 0.0942 & $-60.07 \%$ & $\$ 2,462,685$ & $12.35 \%$ & $\$ 956,244$ & $38.83 \%$ \\
\hline
\end{tabular}

\section{References}

Akkermans, H., Van Oppen, W., Wynstra, F., \& Voss, C. (2019). Contracting outsourced services with collaborative key performance indicators. Journal of Operations Management, 65(1), 22-47.

Al-Fawzan, M.A., \& Al-Sultan, K.S. (1997). Economic production quantity for a manufacturing system with a controllable production rate. Production Planning and Control, 8(7), 678-685.

Boucher, T.O. (1987). Maximizing robot production rates for simple insertion operations. IIE Transactions, 19(4), 385-394.

Chiu, S.W., Kuo, J.S., Chiu, Y.S.P., \& Chang, H.H. (2019). Production and distribution decisions for a multiproduct system with component commonality, postponement strategy and quality assurance using a twomachine scheme. Jordan Journal of Mechanical \& Industrial Engineering, 13(2), 105-115. 
International Journal of Mathematical, Engineering and Management Sciences

Vol. 6, No. 3, 787-804, 2021

https://doi.org/10.33889/IJMEMS.2021.6.3.047

Chiu, S.W., Zhao, Z.Y., Chiu, T., \& Chiu, Y.S.P. (2020b). Combining the delayed differentiation policy and common parts' partial outsourcing strategy into a multi-item FPR-based system. Journal of Applied Engineering Science, 18(2), 273-280.

Chiu, Y.S.P., Jhan, J.H., Chiu, V., \& Chiu, S.W. (2020d). Fabrication cycle time and shipment decision for a multiproduct intra-supply chain system with external source and scrap. International Journal of Mathematical, Engineering and Management Sciences, 5(4), 614-630.

Chiu, Y.S.P., Lin, H.D., \& Wu, H.Y. (2020a). Note on cost minimization for a multi-product fabricationdistribution problem with commonality, postponement and quality assurance. Journal of Applied Research and Technology, 18(1), 21-26.

Chiu, Y.S.P., Zhao, Z.Y., Chiu, S.W., \& Chiu, V. (2020c). A vendor-buyer coordinated system featuring an unreliable machine, scrap, outsourcing, and multiple shipments. International Journal of Industrial Engineering Computations, 11(3), 341-358.

Daugherty, P.J., \& Dröge, C. (1997). Organizational structure in divisionalized manufacturers: the potential for outsourcing logistical services. International Journal of Physical Distribution \& Logistics Management, 27(5/6), 337-349.

Demić, M., Rakićević, B., Jovanović, M., \& Miličić, B. (2020). Research into truck transmission torsion vibrations under longitudinal acceleration. Journal of Applied Engineering Science, 18(2), 243-250.

Elahi, E. (2013). Outsourcing through competition: what is the best competition parameter? International Journal of Production Economics, 144(1), 370-382.

Fathallah, B.B., Saidi, R., Dakhli, C., Belhadi, S., \& Yallese, M.A. (2019). Mathematical modelling and optimization of surface quality and productivity in turning process of aisi 12L14 free-cutting steel. International Journal of Industrial Engineering Computations, 10(4), 557-576.

Gerchak, Y., \& Henig, M. (1986). An inventory model with component commonality. Operations Research Letters, 5(3), 157-160.

Gharbi, A., Kenné, J.P., \& Hajji, A. (2006). Operational level-based policies in production rate control of unreliable manufacturing systems with set-ups. International Journal of Production Research, 44(3), 545567.

Glock, C.H., \& Grosse, E.H. (2021). The impact of controllable production rates on the performance of inventory systems: a systematic review of the literature. European Journal of Operational Research, 288(3), 703-720.

İnkaya, T., Armbruster, D., Li, H., \& Kempf, K.G. (2018). Product variety strategies for vertically differentiated products in a two-stage supply chain. International Journal of Production Research, 56(17), 5930-5944.

Iqbal, J., Ahmad, R.B., Khan, M., Fazal-E-Amin, Alyahya, S., Nasir, M.H.N., Akhunzada, A., \& Shoaib, M. (2020). Requirements engineering issues causing software development outsourcing failure. PLoS ONE, 15(4), Art. No. e0229785.

Jabbarzadeh, A., Haughton, M., \& Pourmehdi, F. (2019). A robust optimization model for efficient and green supply chain planning with postponement strategy. International Journal of Production Economics, 214, 266-283.

Le Pape, N., \& Wang, Y. (2020). Can product differentiation mitigate conflicts of interest between principal stakeholders? A cournot-bertrand comparison. Economic Modelling, 91, 341-346.

Lee-Mortimer, A. (2006). Improved product design as an alternative to outsourcing manufacture and assembly. Assembly Automation, 26(2), 121-126. 
International Journal of Mathematical, Engineering and Management Sciences

Vol. 6, No. 3, 787-804, 2021

https://doi.org/10.33889/IJMEMS.2021.6.3.047

Lesmono, D., Limansyah, T., \& Loedy, N. (2020). A joint return policy for a multi-item perishable inventory model with deterministic demands, return and all-units discount. International Journal of Mathematical, Engineering and Management Sciences, 5(3), 416-431.

Lin, H.D., Chen, Y.R., Chiu, V., \& Chiu, Y.S.P. (2019). A decision model for a quality-assured EPQ-based intra-supply chain system considering overtime option. Journal of Applied Engineering Science, 17(3), 362-371.

Moin, C.J., Iqbal, M., Malek, A.B.M.A., \& Haque, R. (2020). Time-based process mapping for lead time compression in the apparel supply chain: a case study. International Journal of Mathematical, Engineering and Management Sciences, 5(1), 96-107.

Nahmias, S. (2009). Production and operations analysis. McGraw-Hill Co. Inc., New York.

Sajadieh, M.S., Larsen, C. (2015). A coordinated manufacturer-retailer model under stochastic demand and production rate. International Journal of Production Economics, 168, 64-70.

Schulze, L., \& Li, L. (2009). A logistics network model for postponement supply chain. International Journal of Applied Mathematics, 39 (2).

Van Mieghem, J.A., \& Dada, M. (1999). Price versus production postponement: capacity and competition. Management Science, 45(12), 1631-1649.

$\mathrm{Wu}$, J., Du, G., \& Jiao, R.J. (2021). Optimal postponement contracting decisions in crowdsourced manufacturing: a three-level game-theoretic model for product family architecting considering subcontracting. European Journal of Operational Research, 291(2), 722-737.

Yadavalli, V.S.S., Udayabaskaran, S., Dora Pravina, C.T., \& Sreelakshmi, S. (2020). A two-stage mutation stochastic model of carcinogenesis driven by a two level random environment. International Journal of Mathematical, Engineering and Management Sciences, 5(6), 1392-1408.

Original content of this work is copyright $\odot$ International Journal of Mathematical, Engineering and Management Sciences. Uses under the Creative Commons Attribution 4.0 International (CC BY 4.0) license at https://creativecommons.org/licenses/by/4.0/ 